\title{
Researcher Identity: Exploring the Transformatory Power of the Research Experience
}

\author{
Kathy Hamilton \\ Department of Marketing, \\ University of Strathclyde Business School, \\ Stenhouse Building, 173 Cathedral Street, \\ Glasgow, G4 0RQ, UK \\ Tel: +441415483240 \\ Fax: +44 1415522802 \\ Email: Kathy.Hamilton@strath.ac.uk
}

Kathy Hamilton is a Senior Lecturer in Marketing at the University of Strathclyde. Her research interests fall within the area of Interpretive Consumer Research or Consumer Culture Theory. Specifically she is interested in consumer disadvantage, gender issues in consumer behaviour, celebrity consumption and the consumption of dance. Her work has been published in journals such as European Journal of Marketing, Journal of Consumer Behaviour, Journal of Marketing Management and Advances in Consumer Research.

\author{
Susan Dunnett* \\ University of Edinburgh Business School \\ 29, Buccleuch Place \\ Edinburgh, EH8 9JS, UK \\ Tel: +441316503814 \\ Fax: +441316513197 \\ Email: Susan.Dunnett@ed.ac.uk
}

Susan Dunnett is a Lecturer is Marketing at the University of Edinburgh. Her research is conducted within the interpretivist consumer research tradition; areas of interest are consumer identity, collective practices, critical marketing and research methods. She has a longstanding interest in the experience of illness and the consumption of healthcare.

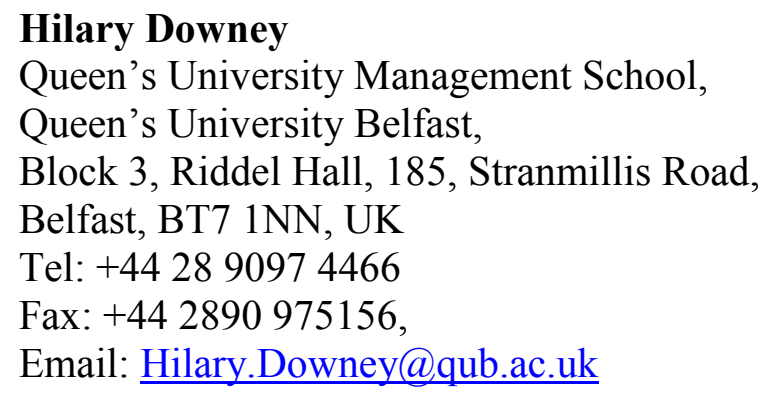

Hilary Downey is a Lecturer in Management in Queen's University Belfast. Her research interests fall within the area of Interpretive Consumer Research, Consumer Culture Theory and Transformative Consumer research. Her research interests address consumer vulnerability, disability, identity and consumption, social justice, and well-being. Publications include Journal of Public Policy and Marketing, European Journal of Marketing, Advances in Consumer Research, and the International Journal of Sociology and Social Policy. 


\title{
Researcher Identity: Exploring the Transformatory Power of the Research Experience
}

\begin{abstract}
In consumer research we frequently focus on the phenomenon of transformation; be that the transformatory effects of a particular consumption community or the great body of work being carried out under the banner of Transformative Consumer Research. However there is a particular transformation which occurs in the field of interpretivist consumer research that, we would argue, is overlooked - that of researcher transformation. We present as data our reflexive considerations on the ways in which our own research with vulnerable consumers has affected and changed us. We consider short term transformations in the field, reflecting on the various ways that researcher identity is carefully managed and negotiated to fit with the socialcultural setting. We also consider longer term transformations and discuss the enduring impact of the research process - the people we have met, the homes we have visited and the stories we have heard. By reflecting on the shaping of identities 'in the field' we aim to deepen our appreciation of the interpretive consumer research process and contribute to theoretical understanding of transformative identity research.
\end{abstract}

Keywords: Transformative Consumer Research, researcher identity, researcher transformation, vulnerable consumers, interpretive research 


\section{Researcher Identity: Exploring the Transformatory Power of the Research Experience}

In consumer research we frequently focus on the phenomenon of transformation (Schouten, 1991); be that the transformatory effects of a particular consumption community (cf Belk and Costa, 1998) or the great body of work being carried out under the banner of Transformative Consumer Research (Mick, 2006). However there is a particular transformation which occurs in the field of interpretivist consumer research that, we would argue, is overlooked - that of researcher transformation. Previous work has highlighted how researchers working in sensitive contexts have the potential to feel vulnerable (Downey et al. 2007). However, there has been little focus on the lasting impact of the research process and how it can change us both as consumer researchers and as human beings.

In this paper we explicitly view the research process as a transformatory one. Reinharz (1997) talks of the construction of the researcher-self in the field stating that 'we both bring the self to the field and create the self in the field' (ibid: 3). Similarly, Humphries, Brown and Hatch, (2003: 9) suggest that 'the discovery of the self is an integral aspect of discovering the other'. While Coffey (1999: 1) highlights the personal nature of research, seeing it as a kind of 'identity work' that constructs and produces researcher identity both during and after fieldwork. Interaction with research contexts and informants provides a new vantage point from which to critically view the self, as we become accustomed to the 'looking-glass self' and viewing ourselves through the eyes of others (Mead, 1934). 
In the following section, we turn to the literature and discuss the limited, but important work that informs our understanding of researcher transformation, drawing on both consumer research and work from other disciplines. Next, we present the ways in which our own research with vulnerable consumers has affected and changed us. We consider short term transformations in the field, reflecting on the various ways that researcher identity is carefully managed and negotiated to fit with the socialcultural setting. We also consider longer term transformations and discuss the enduring impact of the people we have met, the homes we have visited and the stories we have heard. In addition we share insight from conversations with fellow researchers. By reflecting on the shaping of identities 'in the field' our aim is to deepen our appreciation of the interpretive consumer research process and contribute to the theoretical understanding of transformative identity research.

\section{Researcher Identity}

It is widely recognised that the self-concept is malleable and dynamic; we change throughout our life course and display different versions of self depending on the context we find ourselves in and the people with whom we are interacting. Hopson and Adams (1976) highlight that transitions or discontinuities can create identity strain. Similarly, Giddens $(1991: 33,52)$ suggests that self-identity is always a workin-progress; transitions in individual lives demand 'psychic organisation' as identity 'is not something that is just given, as a result of the continuities of the individual's action-system, but something that has to be routinely created and sustained in the reflexive activities of the individual.' Consumer researchers have also recognised that transitions can have an impact on identity formation by creating a limbo between a 
past state and a coming one, 'a period of personal ambiguity, of non-status, and of unanchored identity' (Schouten, 1991: 49). It is generally acknowledged that efforts are made to resolve these identity conflicts (Burroughs and Rindfleisch, 2002; Mick and Fournier, 1998; Murray, 2002) by locating periods of transitions into new narratives of the self (Shankar et al. 2001). We hold that the researcher's identity is similarly challenged as they move through the research process. As yet, research on this topic remains underdeveloped. As Dickson-Swift et al. (2007: 329) argue, 'very little empirical work focusing directly on the experiences of researchers has been undertaken to date.' In this paper, we aim to address this gap by focusing on the concept of researcher transformation.

\section{Researcher Transformation}

"When researchers do gain entry into the private worlds of others they have the potential to invade, distort or destroy parts of the private world. If participants in sensitive research open themselves to this type of research they are also opening themselves to the possibility that they may be somehow changed by the process. This is also true for the researchers. Researchers also open up some of themselves to the participants and in doing so render themselves vulnerable to change" (Dickson-Swift et al. 2008: 10).

It is commonly acknowledged that the researcher has an impact on both the research process and the construction of knowledge (Bettany and Woodruffe-Burton 2009). However, the two-way nature of the researcher-researched relationship is often overlooked. Within the methodological literature on ethnography, it is recognised that the 
researcher is a research instrument who performs a pivotal role in data collection. Atkinson and Hammersley (2007) suggest that researchers may engage in impression management to facilitate access and should remain aware of self-presentation issues. These short-term transformations may involve changes in dress, language or demeanour or, in other words, active construction of different researcher selves to facilitate immersion in the chosen context and hence, generate good data. However, researcher transformations of a deeper character or those which extend beyond the fieldwork site are not often considered. In this paper, we argue that such transformations are not only experienced by researchers involved in ethnographic projects, but also by researchers engaged in less immersive qualitative work. Following Dickson-Swift et al. (2008), we pay particular attention to researchers working on sensitive topics. Given that the Transformative Consumer Research agenda is concerned with transforming lives of those considered vulnerable (for example, homelessness, health issues, disasters, consumer misbehaviours), it is important that we consider how researchers investigating such challenging topics are affected and changed by their work.

Ozanne and Fischer (2011) end their methodology-focused chapter in the recently published Transformative Consumer Research volume with the following caution: 'be prepared to be profoundly changed.' In particular, they refer to two types of transformation. Firstly, they suggest that, through a social comparison process, researchers focusing on marginalised or vulnerable groups come to better appreciate their own situations. Secondly, they suggest that conducting research in sensitive contexts may instil a sense of duty and social justice and a need to instigate change that could improve respondents' lives. In this respect, researchers' focus may extend 
beyond purely academic outputs as they strive to make a practical difference to the lives of those they study. In the remainder of this section, we discuss some examples of transformation experienced by researchers working in sensitive contexts. Personal reflections on such transformations remain limited in the marketing and consumer research literature discipline, and we draw on material from both within and beyond the disciplinary confines.

Stone's (2009) study of elderly consumers in a care home provides an interesting starting point from which to demonstrate how hermeneutic interpretation can have a lasting emotional impact. Drawing on introspective reflections, Stone (2009: 224-225) illustrates how one interview, during which the participant confessed to attempted suicide, has remained with him. He reveals, 'I became quite withdrawn, self-centred, lethargic, moody and generally unpleasant.' The multiple re-readings of the interview transcripts required for phenomenological work intensified these feelings: 'Each time a new revelation hit me - and I swear I could physically feel these impacts - I seemed to sink into a deeper and deeper sense of depression.' Woodthrope's (2007: 3) ethnographic work on meanings in the cemetery landscape provides another interesting example of how research can become an intellectual and emotional journey.' Her account is effective in reminding us that often, the transformatory power of the research experience is unanticipated: 'Whilst I was aware of being the vessel through which this data would be collated, at this stage I did not consider how my human-ness would affect what I saw, how I saw it, and what I recorded.' (ibid: 4). As a consequence of spending time in a cemetery Woodthrope $(2007: 4,6)$ found herself 'becoming increasingly sensitised to issues surrounding grief and mourning' to the extent that she 'had become excessively concerned about death.' 
While the examples above demonstrate the emotional impact of conducting research on sensitive topics, the opposite can also be true in that researchers can become desensitised. In other words, an issue that may be regarded as emotionally charged in advance of the research may become less so as the research progresses. One of the participants in Dickson-Swift et al.'s (2007) study provides an illuminating example '...it's like those sorts of things just wear off, you know you don't get a shock when someone says- "oh my father beat me for 10 years," you just think "oh well"”. Scott (1998: 2, 3) shares similar sentiments in her account of research on ritual abuse: 'Unlikely as it may seem, ritual abuse had become part of my taken-for-granted knowledge of the world by the time I began this research.'

It is also important to acknowledge that research in seemingly non-sensitive contexts can have an equally transformative impact on the researcher. Coffey's (1999: 26) work on the ethnographer-self reminds us that fieldwork is always personal in nature in terms of the way it constructs, shapes and challenges the researcher. She argues that research can have a 'lasting impact on the conceptualization of selfhood beyond the temporal and spatial boundaries of fieldwork.' In other words, it is not only fieldwork carried out in sensitive contexts that can have a transformative impact on our lives that extends beyond academic boundaries. To illustrate, Canniford's (2007) reflections on his ethnographic study of the global surfing subculture reveal the physical and emotional challenges that he experienced on exiting the field:

'At some stage the ethnographer-seamonster must crawl from the water's edge, amble up the beach, slump into a car and creep back towards civilisation.......Long periods over the last few years have been spent at University, about an hour away from good 
surf. Periods of the last three years have seen me effectively quit surfing. During these times my ability as a surfer has sunk to more deplorable levels than usual; my body has become soft and ineffective in the water. At times I have become depressed and taken to shutting myself in a dark room to meditate myself onto a glassy green wave.'

\section{A Note on method}

Each of the authors has conducted separate research studies in sensitive contexts relating to life-threatening illness, disability and poverty. All the studies involved a constructionist ontology, in-depth interviews and non-participant observation. As a starting point to data collection we each generated a written piece of reflection on our research process, focussing on the theme of transformation. These reflections relate to our completed doctoral research projects. We did not have a rigid structure in place for this document and were at liberty to capture our reflections and interpretations in a manner we considered appropriate. We present as data our reflexive considerations extracted from these documents on the ways in which our research projects changed us. Change is a notoriously difficult phenomenon to diagnose in oneself and therefore we have analysed each other's accounts to derive nascent findings. We have found this collective (The Voice Group, 2008) way of working helpful in generating a form of "interpretive community" (Thompson, 2002), one which has allowed us to distance ourselves from our own stories and view our experiences through the eyes of others.

This, sometimes controversial (Wallendorf and Brucks, 1993) approach to data collection is relatively uncommon but is certainly not new. In bringing ourselves more explicitly into our study we follow in the introspective footsteps of Gould (1995), 
auto-ethnographers (Hackley, 2007) and those who share their valuable reflexive accounts of the research process (cf Bettany and Woodruff-Burton, 2009). Rojas Gaviria and Bluemelhuber (2010) make similar use of what they term 'guided introspection' (ibid: 130) to explore the researcher/consumer's experiences of life transition and we concur with their sentiment that introspection is a "natural first step in many of our consumer research projects' (ibid: 130), whether acknowledged or not.

We add to our own reflexive data with anecdotal accounts from colleagues working with interpretivist methods in similar contexts. These observations were conveyed to us through face-to-face, email and telephone conversations and have enabled us to both contextualise and validate our own interpretations. Again, reflective pieces from other colleagues draw on understandings of completed research projects. In addition to our own reflections we present anonymised data from these interactions with the kind permission of our colleagues. What we offer here is an exploratory study with the modest aim of uncovering and understanding hidden aspects of the consumer research process.

\section{Findings: Reflections of Researcher Transformation}

We draw on Turner's (1967) stages of transition to illustrate the (re)construction of researcher identity; we organise the findings around the themes of separation, liminality and reincorporation. It is worth noting that these stages do not represent a neat and linear progression, it is difficult to define where one ends and the next begins as stages segue into one another, yet they provide a useful framework with which to explore researcher transformation and structure the discussion of the data. 


\section{Separation}

The first phase relates to the way in which we attempt to embrace a new researcher identity as we begin data collection. This stage removes us from our previous roles as we engage with new contexts and people. Undoubtedly the initial phases of fieldwork are met with feelings of excitement. After months of literature reviews and methodological decisions, it is refreshing and energising to finally come face to face with respondents:

As academics we spend a lot of time alone in our offices or "alone" at the front of the class, fieldwork takes us away from this setting and makes us engage with the world in a new way. It can be an exhilarating experience.

As I sought access to respondents via local community organisations I felt that my disciplinary background was a hindrance and grew increasingly frustrated at the scepticism I met from potential gatekeepers who questioned my motives. So after months of closed doors I was finally getting to speak to people, finally I was a researcher. The feelings of doubt started to slip away. I was in the field and although I had new challenges to face, my study had officially begun.

Although exciting, entering the field can be demanding, bringing with it feelings of anxiety and a desire to get things right, to be professional. Prior immersion in the research methods literature reinforces this sense of responsibility. McCracken in his seminal piece on the long interview (1988: 21 emphasis added) uses strong language to make clear what is at stake: "At crucial moments in the interview, the entire 
success of the enterprise depends upon drawing out the respondent in precisely the right manner. An error here can prevent the capture of the categories and logic used by the respondent." Our reflections reveal that we were keenly aware of the risk of failure. Interviews are fraught with problems, fears and potential pitfalls: not only "one shot" to get it right but their contrived nature and artificiality, short time frame, the difficulties of building trust and creating rapport. Much of this relates to the fact that we are researching topics that are outside our norms. As researchers, we are strangers, attempting to enter a research field that is constructed as elsewhere: how should we access this foreign land?

So my first attempt in the field at about the age of 24/25, using knowledge from the literature to communicate with these vulnerable people, led me to open up a conversation with the words, 'You are a vulnerable consumer, from rural [Midwestern state], I have come to talk to you.' You can imagine how these people were made to feel as they had never been described as vulnerable before and they certainly didn't see themselves as such. This really brought it home to me, I felt as if I had been beaten over the head. I was coming from an ivory tower perspective that doesn't really have a clue, the literature had illprepared me for the field.

During the initial fieldwork phase this 'foreignness' can be difficult to ignore. As researchers, we encounter places and people which are new to us. 
My fieldwork was conducted in another country, one which I had visited but not lived in. Contextualisation took some time; you have to build a life in this new setting.

I went into the field not realising how far removed my respondents' everyday life experiences were from my own. Different family circumstances, different educational background, fear of the future versus a looking forward to the future. The comparisons were glaringly obvious and difficult to ignore.

As the extracts above indicate, fieldwork with vulnerable groups can involve a physical distancing as we move to new geographic locations. It can also create a kind of self-distancing in that we become aware of how others see us, we become aware of 'difficult differences' (Reay, 1996: 443) that exist between us and our informants. This provides a new vantage point from which to view our lives (Ozanne and Fischer, 2011), separating us from that which we took for granted. The way in which we adapt to such distancing has a strong influence on the emergence of the researcher self. Ahuvia (2005) writes of the fragility of such identity positions: "Throughout their lives, people strive to resolve identity conflicts, although the ongoing nature of life renders each resolution inherently tentative and imperfect." (ibid: 181). This separation phase involves mixed feelings as we experience both positive and negative changes, everything is new and the result is conflicting identities and emotions as we deal with various challenges and adapt to the new skills required of us. These feelings are not easily resolved and indeed continue throughout the fieldwork experience and beyond. 


\section{Liminality}

Turner analyzed society as a 'structure of positions' (Turner, 1967: 93) where the liminal stage marks the transition between two socially viable positions. Liminality, according to Turner (1974: 274), 'is a movement between fixed points and is essentially ambiguous, unsettled, and unsettling.' The biggest challenge to researcher identity during this phase is defining what role the researcher should play during fieldwork. What is our 'socially viable' position? How can we avoid liminal feelings of vagueness and illogicality (Turner 1967)?

Embracing the role of researcher can require a shift in identities. Two examples of this conflicted transition are provided below. The first relates to changing personal relationships with reference to the challenges of conducting research with those we know, as the boundaries between friend and research subject become blurred. The second relates to a change in professional role:

Starting out as friends, confidantes, sharing in the intimate experiences of the ups and downs of everyday life, only to be challenged by the aspirations of a researcher who wanted to be immersed in the 'blood, sweat and tears' of what informants' lives were really like. Feeling it, sharing it, is a natural and comforting part of friendship, but separating friend from researcher and vice versa, calls Jekyll and Hyde to mind. The knowledge that I could tap into the nuances of [their experiences] (as a friend) seemed one less hurdle to overcome, but the wearing of two hats (friend and researcher), playing two roles at one time did not seem so privileged a position after all. 
At first the role of non-participant observer feels foreign to me. In my previous career I set up and facilitated cancer support groups and now I find myself silently looking on. The passivity of it makes me feel redundant, I realise I need to embrace the new researcher self.

As researchers we seek immersion in fieldwork sites as we engage in context building. The insider perspective is often celebrated as the best route to knowledge generation in that a researcher who has a lived familiarity with the group under study will have access to a different, more authentic type of knowledge to the outsider. Or put more simply, 'you have to be one in order to understand one' (Merton 1972: 15). In many cases, we shared biographical markers with those we interviewed (for example, age, gender, race) however, we lacked lived familiarity with the severe vulnerabilities our informants experienced. As a result we took on various short-term transformations in efforts to seek better rapport with our participants.

I developed an interview uniform: a plain black top, jeans, black shoes, black bag, and limited jewellery. No brand names or logos in sight. I arrived at their homes via public transport, never in a car. I didn't want to do anything that would highlight the financial difference between my position and their position.

However, while these short-term transformations were actively constructed in efforts to improve rapport, we also experienced other transformations that were outside our control. These problems of adaption were heightened because the sensitive contexts added a significant emotional element. Researchers in this area become not only 
aware of the risks of failure but also the risks of emotional exposure, something which we are often not adequately prepared for:

My research aim related to coping strategies so it seems somewhat ironic that I didn't think to devise any coping strategies for myself. I didn't have a preplanned method of emotional management, no way of dealing with the emotional intensity of the stories I heard and the empathy I felt. Emotions were concealed, only reflected on a later date when the PhD was complete.

Often interviews would emotionally deplete me. It is a bitter-sweet thing to be welcomed into the lives and homes of people who experience great pain and face great adversity.

Immersion meant that the emotional intensity of our reactions was a necessary part of our fieldwork experiences. Conventional wisdom dictates that the researcher begins as stranger and progresses towards familiarity but also maintains the professional distance required for analysis, interpretation and delivery of theoretical contributions. However, the reality is more complicated than this:

As I walked into peoples' homes, received their hospitality - ate lunch, dinner and cookies, drank lemonade - the armoury, the distance, of the researcherself I brought to the field melted away. While I toured homes and admired remodelled bathrooms, met dogs and cats, viewed photographs of children and grandchildren (and one couple's wedding album) a new researcher-self 
developed; an empathetic listener, a partner in conversation, a temporary community member. The impartial observer was gone.

As illustrated above, researchers can gain glimpses into private spheres of respondents' lives. Common to all our studies was the warm welcomes we received when entering our respondents' homes. As a result maintaining the role of a distanced, impartial researcher was impossible and we experienced identity conflict between friendliness and professional distance. Firat and Venkatesh (1995) describe the fragmented self, suggesting that there is no requirement to reconcile one identity with another. Our narratives of transition contradict this in their depiction of the difficultly and cognitive dissonance engendered by moving between the known self and the new researcher self.

As researchers, we endeavoured to facilitate rapport and openness. Somewhat unexpectedly, it became apparent that participant disclosure was not going to be a problem and indeed, it was sometimes surprising just how much participants were willing to reveal. This calls to mind Simmel's (1908) writings on the stranger. In some senses, our role as researcher might be considered as 'the stranger who moves on' who 'often receives the most surprising revelations and confidences, at times reminiscent of a confessional, about matters which are kept carefully hidden from everybody with whom one is close' (Simmel, 1908: 237).

Being the confidant for innermost thoughts and feelings reminded me that I was both a consumer researcher and a human being. Upon hearing stories of heart-break, hardship, grief and depression, I experienced conflicting and 
shifting emotions. My researcher self was elated at the good data that would undoubtedly become important in informing my research contribution. Yet my human self was filled with compassion. The conflict between these extremes of emotions often created feelings of guilt.

This experience of role ambiguity is perhaps more pressing when researching friends:

These early experiences of the [sensitive] context were like being slapped across the face with a wet rag. I was left in complete shock at the lack of understanding and compassion shown by care workers who are supposed to be empathic. Standing on the sidelines looking in at everyday life, as researcher/friend you are caught between two often conflicting states.

Another role paradox that became evident related to the outcomes we desired from our research. Echoing the caution offered by Ozanne and Fischer (2011), we wanted to make a difference that extended beyond the academic contributions of our work, yet sometimes grew frustrated at the powerlessness we experienced whilst trying to do so:

It was at this point that it really hit me, this is a big commitment. I remember thinking I have just made a commitment to this community. This was never a problem when conducting interviews with individuals but this was overwhelming and again I was not prepared for this. As a consequence I found myself being propelled deeper and deeper into the community. I felt a responsibility to them. 
I became more passionate about my topic as time passed. As I learnt more about [sensitive context] and encountered it in real life, I had a stronger desire to make some kind of difference. I grew more confident in terms of contacting key change agents in relevant organisations to tell them about my work.

Whilst the desire for social change may have been strong in the field, the reincorporation phase brought our focus back to academic contributions.

\section{Re-incorporation}

This third and final phase refers to exiting the field, returning to life and reincorporating our work into institutional frameworks. Sometimes this was a difficult task: 'Returning from the field was hard - leaving behind a life I had built there and relationships forged. It felt anticlimactic.' It is important to clarify from the outset that although we exit the field we do not simply leave it behind. Canniford (2007) writes evocatively of this:

Now he must dust the sand from his leathery flesh; endeavour to clean the salt from his hair; doff board-shorts; don tweed jacket, and step into a university library. His evolution complete, the only clues as to this species's origin are the flipflops he forgot to change for shoes; the shell he kept in his pocket that has become a holy relic; and the sound of breaking waves he thinks he hears as he turns the pages of a book. 
We take with us the physical and emotional reminders of the researcher-self and we relive our fieldwork experiences many times during data analysis and through our attempts to disseminate our findings.

Exiting the field or ceasing data collection can provide a welcome return to our "real life". Indeed, for those researching friends it can reduce the pressure on friendships as informants are reincorporated 'back to status of friends' which can be instrumental in helping to erase experiences of liminality. However, the responsibility to adequately represent respondents' lives can be keenly felt.

Funnily enough, reviewers didn't think too much of this research, all I seemed to hear was 'this isn't good enough'. I'm thinking, - 'I'm letting a whole town down

(Re)incorporating our work into the extant literature raised a common issue that we all grappled with, this was the use of terminology. How should we refer to our respondents?

Over time I noticed I had stopped referring to my informants as "cancer patients" and began to refer to them as "healthcare consumers".

My friends, Jay, Gloria, Barbara and David evolved to being labelled 'homebound.' I have never thought of my friends as disabled or different but society has a way of stamping 'outsider hood' on those who for various reasons become cut off from positions within the social system. 
Low-income consumers? Poor consumers? Resource-limited consumers? Constrained consumers? Socially excluded consumers? Which of these would sound less negatively laden?

Our decisions were often informed by what we thought would be most acceptable within the discipline, yet at the same time we wanted to avoid dehumanising or sentimentalising our informants. For one of the authors, the re-incorporation phase has resulted in a new way of thinking about the dissemination process. The writing and reciting of poetry has offered a more emotional outlet for tackling and communicating key episodes of transformation and has allowed the chance to move away from the 'stilted [often] dehumanizing way that we strip beloved people of their dignity by reducing them to "consumers," "informants," and "targets"' (Wijland et al, 2011, in Coyotes Confessions Totems).

Many of the challenges to reincorporation related to the reactions of peers and colleagues. Those working in the Transformative Consumer Research arena can strongly feel institutional pressures to justify their choice of research subject. We emerge from the field transformed, enthusiastic and energised, hoping that our research may matter. We are ready to share our findings but quickly realise that this task brings with it a range of barriers that we will have to overcome. Journal requirements, reviewer comments, expectations and limited understanding from colleagues in our business schools all combine to induce more challenges and changes. 
Sometimes I felt compelled to frame my study in terms of the resulting marketing and managerial implications. Although such a framing didn't do justice nor adequately reflect what my research was really about, this appeared to produce a more "legitimate" account.

[T]here is the conflict between my wanting to do something for "my community" and my institution needing/ driving your decisions about your research focus. Other disciplines, Economic Geographers, Sociologists/Anthropologists have taken an interest in my work and this is good but again in a management context publication in particular journals are still the important indicator of quality research.

The clear subtext to some of our interactions with disciplinary gatekeepers was that these contexts were not suitable for study within marketing. To illustrate, we include below some anonymised excerpts taken from reviewer feedback that we have received.

"I think the link between the [particular sensitive context] and consumer research is far-fetched. From my point of view is [sic] consumer research a very broad discipline, but I'm not convinced [sic] that this kind of communities should be included in the field" (Review from an international consumer research conference, 2007).

"We definitely would not recommend politicians to act based on a bunch of personal opinions. So we need something generalizable and evident. The 
authors use partly subjective findings from the interviews to trigger changes in public policy. This is not what science is supposed to do" (A leading policyfocussed journal, 2006).

"[Authors should]...not descend into the kind of reformist and elitist language that afflicts some of the TCR rhetoric...........perhaps we should simply leave the vulnerable alone" (A cultural consumer research conference, 2009).

Collectively these comments illustrate the pressure that is placed upon researcher identity for those working in topics that may be considered outside the marketing mainstream and we hope that sharing our reviewer comments may prove useful to others who have faced similar criticism. Such questioning of the validity of our research topics acts as a direct barrier to academic reincorporation - where do I belong if my discipline rejects me?

\section{Conclusions}

This paper sought to highlight the concept of researcher transformation with particular reference to those working in sensitive contexts. As we endeavour to conduct robust studies, carryout thoughtful, useful interviews while respecting and protecting both the informants and ourselves, we go through various changes. These transformations are also connected to the multiple roles we take on throughout the research process insider, outsider, friend, professional researcher, academic writer, social change agent. Some are short-term practical changes (adapting researchers' style of dress or language) that are consciously driven by our desire to generate high quality data. 
Other changes arise more unexpectedly, sometimes hitting us with an emotional intensity that we are ill-prepared for. While some may argue that the recognition of researcher emotions challenges research objectivity, we counter that there is an intrinsic value to the experiencing, and particularly to the recognition, of strong emotions encountered throughout the research process. We follow Woodthrope (2007) and suggest that emotional responses can reveal important insights. Our emotional reactions 'act as a 'doorway' to the inner terrain of people' (Watts, 2008: 8) and allow us to view the research process in a deeper way. Researcher transformation therefore extends beyond the careful management of appearance and other practical 'impression management' strategies (Atkinson and Hammersley, 2007) that are discussed in the ethnographic literature. As Brownlie notes, in order to make sense of it, researchers divide the world into 'us, them and it' (Brownlie, 2008: 522). We undertake a process of 'othering' the researched. This observation on 'othering' can be broadened to contend that we ourselves are 'othered' by the research experience when we take on the role of outsider looking in. The challenges of seeking out and understanding consumers' sometimes difficult and painful experiences engender this sense of otherness in the researcher. The emotional and sometimes physical changes experienced by researchers are a symptom of this position of 'other'. As Ahuvia (2005) highlights, identities are unstable, they shift and move, and a new sense of balance must be sought. Narratives of identity allow us to make sense of who we are, were and might become and can therefore be understood as coping mechanisms in themselves. We would argue that for the researcher - as with the researched - telling one's story can be a form of catharsis (Brannen, 1993; Lupton, 1998). This story telling can take the form of fieldnotes as in the case of Canniford (2007), introspection (Stone, 2009), reflexive accounts (Bettany and Woodruffe-Burton, 
2009), poetry (Hill, 2011) or simply through informal conversations with colleagues, friends and family (Dickson-Swift et al. 2007). Turn[er]ing moments have provided a framework for such narratives to breathe life into the concept of researcher transformation. Our transformations are borne of the sense of separation and liminality experienced over the duration of the research process. As we have illustrated, this sense of 'otherness' or 'outsiderhood' is not confined to the field, it can also be felt within the confines of the Business School. We continue with the identity work begun in the field and attempt to mould our researcher-selves anew to suit the demands placed on us as academics.

The current study offers several avenues for future research. The majority of the reflections used in this paper relate to doctoral and early career research. Future research could encompass a wider range of perspectives by involving those at different stages of their career. Additionally, all the reflective data presented in the paper relates to completed research projects. It is possible that researcher transformation may vary at different stages of the research process and future studies drawing on data collected at different stages (for example, during data collection and data interpretation) may provide deeper insights into researchers' identity transformations. Although our focus has been on researcher reflection, another avenue for future research could be the collection of reflexive data from informants in relation to their perceptions of the research process and the researcher. This could provide valuable insight into the 'looking-glass self' Mead (1934) speaks of to provide a deeper understanding of their role of the researcher in knowledge generation. Such a perspective may be valuably informed by work in psychotherapy on the concepts of transference and counter-transference (Hacker 1982). We have 
suggested that reflective writing offers a useful way of identifying and coping with identity conflicts. Future research could highlight alternative approaches available to researchers experiencing conflicting identities and emotions.

We began this paper with a modest aim - to explore and illustrate the notion of researcher transformation. By uncovering and understanding a little more of the research process we demonstrate the humanity and empathy that can be at its heart. We close with a poem which seeks to capture and make sense of a moment of researcher transformation experienced by one of the authors:

An invited guest into your world of exclusion,

I care to share in elusively-eclipsed lived experiences

Kept under wraps from societal eyes,

At times, I flounder to become as one

With consumers deemed feckless, flawed, fragmented,

Only to emerge from the field of constrained consumption

Replenished, raw, rejuvenated,

Sensitively stirred by nuanced understandings,

Re-washed in self-vulnerability, transformed by the power

Of the research experience. 


\section{References}

Ahuvia AC, 2005. Beyond the Extended Self: Loved Objects and Consumers' Identity Narratives. Journal of Consumer Research 32, No. 1 (June): 171-184.

Atkinson P, Hammersley M. 2007. Ethnography: Principles in Practice. Routledge, London.

Belk RW, Costa AJ. 1998. The Mountain Man Myth: A Contemporary Consuming Fantasy. Journal of Consumer Research 25 (December): 218-240.

Bettany S, Woodruffe-Burton H. 2009. Working the limits of method: the possibilities of critical reflexive practice in marketing and consumer research. Journal of Marketing Management 25 (7-8): 661-679.

Brannen J. 1993. The Effects of Research on Participants: The Findings from a Study of Mothers and Employment. The Sociological Review 41: 415-424.

Brownlie D. 2008. Relationship Climate Canaries: A Commentary Mosteller Inspires. Journal of Business Research 61: 522-524.

Burroughs JE, Reindfleisch A. 2002. Materialism and Well-being: A Conflicting Values Perspective. Journal of Consumer Research 29 (3): 348-370.

Canniford R. 2007. Civilising Surfers. Unpublished PhD thesis, University of Exeter.

Coffey A. 1999. The Ethnographic Self: Fieldwork and the Representation of Identity. Sage: London.

Deschenes J. 2007. Behind Closed Doors: Reflecting on the Emotional Challenges of Doing Consumer Research on Painful Topics. Advances in Consumer Research 34: 20-21.

Dickson-Swift V, James EL, Kippen S, Liamputtong P. 2007. Doing sensitive research: what challenges do qualitative researchers face? Qualitative Research 7 (3): $327-353$. 
Dickson-Swift V, James EL, Liamputtong P. 2008. Undertaking Sensitive Research in Health and Social Sciences. Cambridge University Press: Cambridge.

Downey H, Hamilton K, Catterall M. 2007. Researching Vulnerability: What about the Researcher? European Journal of Marketing 41 (7/8): 734-739.

Firat AF, Venkatesh A, 1995, Liberatory Postmodernism and the Reenchantment of Consumption. Journal of Consumer Research, 22 (December): 239-267.

Giddens A. 1991. Modernity and Self-identity. Stanford University Press: Stanford, CA.

Gould, S.J. 1995. Researcher Introspection as a Method in Consumer Research: Applications, Issues and Implications Journal of Consumer Research 21(4): 719-22.

Hacker, H. 1982. Transference and Countertransference, Karnac Books, London.

Hackley, C. 2007. Auto-ethnographic consumer research and creative nonfiction: Exploring connections and contrasts from a literary perspective Qualitative Market Research: An International Journal, 10 (1): 98 - 108.

Hopson B, Adams J. 1976. Towards an Understanding of Transition: Defining Some Boundaries of Transition Dynamics, in Transition: Understanding and Managing Personal Change, J Adams, J Hayes, B Hopson (eds). Martin Robertson: London: 3-25.

Humphreys M, Brown AD, Hatch MJ. 2003. Is Ethnography Jazz? Organization 10 (1): 5-31.

Lupton D. 1998. The Emotional Self, London, Sage.

McCracken G. 1988. The Long Interview, London, Sage. 
Mead GH. 1934. Mind, self and society. Chicago, University of Chicago Press.

Merton RK. 1972. Insiders and Outsiders: A Chapter in the Sociology of Knowledge. The American Journal of Sociology 78 (1): 9-47.

Mick DG. 2006. Presidential Address: Meaning and Mattering through Transformative Consumer Research. Advances in Consumer Research 33, 1-4.

Mick DG, Fournier S. 1998. Paradoxes of Technology: Consumer Cognizance, Emotions, and Coping Strategies. Journal of Consumer Research 25 (Sept): 123-143.

Murray JB. 2002. The Politics of Consumption: A Re-Inquiry on Thompson and Haytko’s (1997) 'Speaking of Fashion'. Journal of Consumer Research 29 (3): 427-440.

Ozanne J, Fischer E. 2011. Sensitizing Principles and Practices Central to Social Change Methodologies, in Transformative Consumer Research for Personal and Collective Well-Being, Edited by David Glen Mick, Simone Pettigrew, Cornelia (Connie) Pechmann and Julie L. Ozanne.

Reay D. 1996. 'Dealing with Difficult Differences: Reflexivity and Social Class in Feminist Research.' Feminism \& Psychology 6 (3): 443-456.

Reinharz S. 1997. Who Am I? The Need for a Variety of Selves in the Field, in Reflexivity and Voice, R Hertz (Ed). Sage: Thousand Oaks CA.

Rojas Gaviria P, Bluemelhuber C. 2010. Consumers' transformations in a liquid society: introducing the concepts of autobiographical-concern and desireassemblage. Journal of Consumer Behaviour 9 (2): 126-138.

Schouten JW. 1991. Selves in Transition: Symbolic Consumption in Personal Rites of Passage and Identity Reconstruction. Journal of Consumer Research 17 (March): 412-425. 
Scott S. 1998. Here Be Dragons: Researching the Unbelievable, Hearing the Unthinkable. A Feminist Sociologist in Uncharted Territory. Sociological Research Online 3 (1): http://www.socresonline.org.uk/socresonline/3/3/1.html

Simmel G. 1908. The Stranger in The Pleasure of Sociology. LA Coser (ed). Mentor Book: NY: 235-240.

Shankar A, Elliott R, Goulding C. 2001. 'Understanding Consumption: Contributions from a Narrative Perspective.' Journal of Marketing Management 17 (3-4): 429-453.

Stone T. 2009. Reflections upon the use of existential-phenomenological methods to study elderly consumers in care homes. The Marketing Review 9 (3): 213 229.

The Voice Group 2008. Reflections on collaboration in interpretive consumer research. Qualitative Market Research: An International Journal. 11 (2): 147-165.

Thompson CJ. 2002. A Re-Inquiry on Re-Inquiries: A Postmodern Proposal for a Critical-Reflexive Approach. Journal of Consumer Research 29 (1): 142-145.

Turner V. [1969] 1997. The Ritual Process Structure and Anti-structure, New York, Aldine De Gruyter.

Turner V. 1974. Liminal to Liminoid in Play, Flow, and Ritual: An Essay in Comparative Symbology. Rice University Studies 60 (3): 53-92.

Wallendorf M. and Brucks M. 1993. Introspection in Consumer Behavior: Implementation and Implications, Journal of Consumer Research 20 (December): 339-359.

Watts JH. 2008. Emotion, empathy and exit: reflections on doing ethnographic qualitative research on sensitive topics. Medical Sociology Online, 3(2): 3-14.

Widdowfield R. 2000. The place of emotions in academic research. Area 32 (2): 199-208. 
Wijland R. Sherry J. Schouten J. and Downey H. (eds) 2011. Coyotes Confessions Totems, St. Bathans, New Zealand: University of St. Bathans Press.

Woodthrope K. 2007. My Life after Death: Connecting the field, the findings and the feelings. Anthropology Matters 9 (1): 1-10. 